\title{
QUEBRA DE DORMÊNCIA EM Acacia mangium WILLD E Ormosia arborea (VELL.) HARMS
}

\author{
${ }^{1}$ Hallefy Elias Fernandes, ${ }^{2}$ Edio Lemes da Silva Neto, ${ }^{3}$ Karolinne Pereira Cabral, ${ }^{4}$ Raffael Batista Marques, \\ ${ }^{5}$ Susana Cristine Siebeneichler, ${ }^{6}$ Eduardo Andrea Lemus Erasmo
}

\author{
1Doutorando em Produção Vegetal, Universidade Federal do Tocantins, Campus Gurupi-TO. \\ ${ }^{2}$ Graduado em Agronomia, Universidade Federal do Tocantins, Campus Gurupi-TO. \\ ${ }^{3}$ Graduada em Engenheira Florestal, Universidade Federal do Tocantins, Campus Gurupi-TO. \\ ${ }^{4}$ Graduando em Agronomia, Universidade Federal do Tocantins, Campus Gurupi-TO. \\ ${ }^{5}$ Docente do curso de Agronomia da Universidade Federal do Tocantins, Campus Gurupi-TO. \\ ${ }^{6}$ Docente do curso de Pós-Graduação em Produção Vegetal da Universidade Federal do Tocantins, Campus Gurupi-TO.
}

*Autor para correspondência: Hallefy Elias Fernandes, hallefypgt@hotmail.com

RESUMO: Conhecer os processos que envolvem a germinação e o desenvolvimento da planta é de grande importância para garantir sucesso no plantio futuro. Objetivou-se com este trabalho avaliar métodos de superação da dormência no processo germinativo das sementes de duas espécies florestais: Acacia mangium Willd. e Ormosia arborea (Vell.) Harms. 0 delineamento utilizado foi em blocos casualizados, com 5 tratamentos e 4 repetições com 25 sementes para cada espécie. Para superar a dormência tegumentar, as sementes foram submetidas aos seguintes tratamentos pré-germinativos: T1- imersão em água aquecida a $100{ }^{\circ} \mathrm{C}$, por 1'; T2- imersão em ácido sulfúrico $\left(\mathrm{H}_{2} \mathrm{SO}_{4}\right.$ P.A. por 10'); T3- imersão em ácido sulfúrico $\left(\mathrm{H}_{2} \mathrm{SO}_{4}\right.$ P.A. por $\left.5^{\prime}\right)$ com posterior imersão em água aquecida a $100^{\circ} \mathrm{C}$, por 30 segundos; T4- imersão em ácido sulfúrico $\left(\mathrm{H}_{2} \mathrm{SO}_{4}\right.$ P.A. por $\left.5^{\prime}\right)$ com posterior imersão em água aquecida a $100{ }^{\circ} \mathrm{C}$, por 1 ' e T5- uma testemunha correspondente a sementes intactas sem tratamento prévio. Foram avaliadas as seguintes variáveis: índice de velocidade de germinação (IVG) percentual de sementes germinadas, duras, intumescidas, deterioradas e percentual de plântulas anormais. Com base nos resultados para a superação da dormência das sementes de $A$. mangium recomenda-se o tratamento com água aquecida a 100 ${ }^{\circ} \mathrm{C}$, por 1 'e para as sementes de 0 . arborea foi a imersão em $\mathrm{H}_{2} \mathrm{SO}_{4}$ P.A. por 10', destacando como informações úteis para o meio produtivo das duas espécies avaliadas.

PALAVRAS-CHAVE: espécie florestal, germinação, sementes.

\section{DORMANT BREAKAGE IN Acacia mangium WILLD AND Ormosia arborea (VELL.) HARMS}

\begin{abstract}
Knowing the processes that involve the germination and the development of the plant is of great importance to guarantee success in the future planting. The objective of this work was to evaluate methods of overcoming dormancy in the germination process of the seeds of two forest species: Acacia mangium Willd. and Ormosia arborea (Vell.) Harms. The experimental design was a randomized complete block design with 5 treatments and 4 replicates with 25 seeds for each species. To overcome the integumentary dormancy, the seeds were submitted to the following pre-germination treatments: T1- immersion in water heated at $100^{\circ} \mathrm{C}$, for 1 '; T2immersion in sulfuric acid $\left(\mathrm{H}_{2} \mathrm{SO}_{4}\right.$ P.A. for 10 '); T3- immersion in sulfuric acid $\left(\mathrm{H}_{2} \mathrm{SO}_{4}\right.$ P.A. by 5 ') with subsequent immersion in water heated to $100^{\circ} \mathrm{C}$, for 30 seconds; T4-immersion in sulfuric acid $\left(\mathrm{H}_{2} \mathrm{SO}_{4}\right.$ P.A. by 5 ') with subsequent immersion in water heated at $100^{\circ} \mathrm{C}$ for 1 ' and T5- a control corresponding to intact seeds without pretreatment. The following variables were evaluated: germination speed index (IVG) percentage of germinated seeds, hard, swollen, deteriorated and percentage of abnormal seedlings. Based on the results for the overcoming dormancy of the seeds of $A$. mangium it is recommended to treat with water heated to $100^{\circ} \mathrm{C}$, per 1 'and for the seeds of $\mathrm{O}$. arborea was the immersion in $\mathrm{H}_{2} \mathrm{SO}_{4} \mathrm{PA}$ by 10 ', highlighting as useful information for the productive environment of the two evaluated species.
\end{abstract}

KEY WORDS: forest species, germination, seeds. 


\section{INTRODUÇÃO}

$\mathrm{O}$ aumento dos problemas ambientais e a necessidade de recuperar áreas degradadas tem acarretado interesse referente à propagação de espécies nativas e exóticas (Carvalho et al., 2016; Lucena et al., 2016). Entretanto, estudos disponíveis para produção e análise das sementes ainda são insuficientes (Sampaio et al., 2015).

Diante disso, é de grande importância conhecer os processos que envolvem a germinação e desenvolvimento da planta, para garantir sucesso no plantio futuro. Portanto, um dos processos iniciais é a dormência de sementes, que algumas espécies possuem, a qual se caracteriza pelo atraso da germinação, quando as sementes mesmo em condições favoráveis (umidade, temperatura, luz e oxigênio) não germinam (Carvalho; Nakagawa, 2012; Freitas et al., 2013).

A Acacia mangium Willd. conhecida popularmente no Brasil como acácia australiana, acácia e acácia mangium é uma espécie que se tem mostrado como uma exótica bastante rústica e flexível para diferentes ambientes, sendo utilizada para múltiplos usos como plantios para exploração de madeireira e não madeireira, suas sementes apresentam dormência, sendo considerado como uma das causas, o tegumento impermeável à água (Smiderle et al., 2005).

A espécie Ormosia arborea (Vell.) Harms (olhode-cabra) é uma planta arbórea nativa do Brasil, que proporciona ótima sombra e é ornamental, podendo ser usada na arborização urbana. Pode também ser empregada para plantios mistos destinados à recuperação de áreas degradadas de preservação permanente. Segundo Reis e Freitas (1985), as suas sementes apresentam impermeabilidade do tegumento, com possível presença de inibidores da germinação.

As sementes de cerca de um terço das espécies germinam imediatamente em condições favoráveis, mas as demais apresentam algum grau de dormência (Kramer; Kozlowski, 1972). Segundo Freire et al. (2016), a aplicação de tratamentos pré-germinativos, quando feita de forma eficiente, não danifica o embrião e viabiliza a germinação. A natureza pode realizar esse mesmo processo por ação de microorganismos, fungos ou ácidos fracos do solo e outros. No entanto, para cada espécie é necessária à realização de estudos quanto ao tipo de tratamento e tempo de imersão da semente no ácido ou água, devido à variação na composição e na espessura dos tegumentos (Santos et al., 2011; Giachini et al., 2010; Costa et al., 2010; Cruz et al., 2007). Essa variação também pode ocorrer entre lotes e procedências de uma mesma espécie (Berger et al., 2014; Ladeia et al., 2012; Martins; Nakagawa, 2008).

Portanto, para que essas plantas germinem em uma estação propícia ao seu desenvolvimento e de forma homogênea é necessário realizar a suspensão da dormência. Sendo assim, objetivou-se com este trabalho avaliar métodos de suspensão da dormência no processo germinativo das sementes de duas espécies florestais: $A$. mangium e 0 . arborea.

\section{MATERIAL E MÉTODOS}

O trabalho foi desenvolvido no Laboratório de Ecofisiologia Vegetal da Universidade Federal do Tocantins - Campus Universitário de Gurupi, na cidade de Gurupi, localizada na região sul do estado do Tocantins. As sementes de A. mangium foram obtidas no viveiro Selva Florestal Ltda., enquanto as sementes de 0 . arborea foram coletadas de árvores localizadas na região metropolitana de Porangatu, Goiás, obtidas de frutos respectivamente que tiveram queda espontânea, armazenadas em sacos de papel em temperatura ambiente por um período máximo de 50 dias, em seguida foram submetidas aos tratamentos.

Com relação à assepsia dos materiais utilizados para os experimentos de germinação, foi feita a esterilização dos papéis germitest com outros materiais em autoclave. As sementes foram previamente lavadas com solução de hipoclorito de sódio $(2,5 \%)$ por 1 minuto.

0 delineamento utilizado foi em blocos casualizados, com 5 tratamentos e 4 repetições com 25 sementes para cada espécie. Para superar a dormência tegumentar, as sementes foram submetidas aos seguintes tratamentos pré-germinativos: T1imersão em água aquecida a $100^{\circ} \mathrm{C}$, por 1'; T2- imersão em ácido sulfúrico $\left(\mathrm{H}_{2} \mathrm{SO}_{4}\right.$ P.A. por 10'); T3- imersão em ácido sulfúrico $\left(\mathrm{H}_{2} \mathrm{SO}_{4}\right.$ P.A. por $\left.5^{\prime}\right)$ com posterior imersão em água aquecida a $100^{\circ} \mathrm{C}$, por 30 segundos; T4- imersão em ácido sulfúrico $\left(\mathrm{H}_{2} \mathrm{SO}_{4}\right.$ P.A. por $\left.5^{\prime}\right)$ com posterior imersão em água aquecida a $100{ }^{\circ} \mathrm{C}$, por 1 ' e T5- uma testemunha correspondente a sementes intactas sem tratamento prévio.

Após a aplicação dos tratamentos com ácido sulfúrico, as sementes foram lavadas em água 
corrente, por 2 minutos para eliminar os resíduos do ácido. Em seguida, as sementes foram submetidas ao teste de germinação, utilizando-se quatro repetições de 25 sementes para cada espécie, semeadas em papel germitest, umedecido com água destilada equivalente a 2,5 vezes o peso do papel, em germinador tipo Biochemical Oxigen Demand (B.O.D.), à temperatura $28-33^{\circ} \mathrm{C}$ e fotoperíodo de $8 \mathrm{~h}$.

Foram avaliadas as seguintes variáveis: índice de velocidade de germinação (IVG) percentual de sementes germinadas, duras (sementes que não absorveram água), intumescidas (sementes que absorveram água e não emitiram radícula) e deterioradas (sementes com ataques de fungos ou patógenos externos, com danos a semente e 0 embrião); percentual de plântulas anormais.

Para percentual de sementes germinadas foi usado à fórmula:

$\% G=(S G / T S) \times 100$

Onde: $\% \mathrm{G}=$ percentual de germinação;

$S G=$ número total de sementes germinadas, duras, intumescidas e deterioradas;

$\mathrm{TS}=$ número total de sementes

Seguindo o modelo matemático para percentual de sementes germinadas a mesma fórmula foi utilizada para calcular o percentual de sementes duras, intumescidas e deterioradas substituindo os valores do percentual.

No cálculo do índice de velocidade de germinação foi empregada a fórmula de Maguire (1962):

$\mathrm{IVG}=\mathrm{G} 1 / \mathrm{N} 1+\mathrm{G} 2 / \mathrm{N} 2+\ldots+\mathrm{Gn} / \mathrm{Nn}$;

Onde IVG = índice de velocidade de germinação;

$\mathrm{G} 1, \mathrm{G} 2, \mathrm{G} n$ = número de sementes germinadas computadas na primeira contagem, na segunda contagem e na última contagem.

$\mathrm{N} 1, \mathrm{~N} 2, \mathrm{Nn}=$ número de dias de semeadura à primeira, segunda e última contagem.

As contagens foram realizadas diariamente, por 40 dias, computando-se o número de sementes embebidas e de germinadas. A avaliação de sementes embebidas foi realizada de forma visual. Foram consideradas germinadas as sementes que apresentavam rompimento do tegumento e emissão da radícula. As plântulas normais foram retiradas e computadas quando a contagem de germinação de cada espécie estabilizou.

Os dados de germinação e do índice de velocidade de emergência foram submetidos à análise de variância pelo programa estatístico SISVAR (Ferreira, 2014). A comparação das médias foi realizada pelo teste de Tukey, a $5 \%$ de probabilidade.

\section{RESULTADOS E DISCUSSÃO}

Para as sementes de $A$. mangium os tratamentos com utilização de água fervente (T1, T3 e $\mathrm{T} 4$ ), apresentaram significativamente maior percentual de germinação quando comparados ao tratamento $\mathrm{H}_{2} \mathrm{SO}_{4}$ 10' (T2) e a testemunha (T5). O percentual de sementes intumescidas e deterioradas foi menor para todos os tratamentos, não apresentando prejuízo a condução da germinação das sementes de $A$. mangium (Tabela 1). $\mathrm{O}$ tratamento $\mathrm{H}_{2} \mathrm{SO}_{4}$ 10' (T2) não foi eficiente para quebra da dormência das sementes, pois uma alta porcentagem das sementes permaneceu duras, e não foi observado o intumescimento da semente (Tabela 1). Portanto nas condições deste trabalho o ácido sulfúrico não rompeu o tegumento da semente.

Tabela 1. Índices percentuais de germinação $(G)$, sementes intumescidas (E), sementes duras $(D)$ e sementes deterioradas (Dt) ao fim da contagem de germinação das sementes de Acacia mangium Willd.

\begin{tabular}{|c|c|c|c|c|}
\hline Tratamentos & G (\%) & $E(\%)$ & $\mathrm{D}(\%)$ & $\mathrm{Dt}(\%)$ \\
\hline T1- Água a $100^{\circ} \mathrm{C} 1 '$ & $88,0 \mathrm{a}$ & $6,7 \mathrm{a}$ & $2,6 \mathrm{~b}$ & $2,7 \mathrm{a}$ \\
\hline $\mathrm{T} 2-\mathrm{H}_{2} \mathrm{SO}_{4} 10^{\prime}$ & $9,3 b$ & $9,3 \mathrm{a}$ & $78,6 \mathrm{a}$ & $2,8 \mathrm{a}$ \\
\hline $\mathrm{T} 3-\mathrm{H}_{2} \mathrm{SO}_{4} 5^{\prime}$ + água aquecida a $100{ }^{\circ} \mathrm{C} 0,5^{\prime}$ & $81,3 \mathrm{a}$ & 17,3 a & $00 \mathrm{~b}$ & $1,4 \mathrm{a}$ \\
\hline $\mathrm{T} 4-\mathrm{H}_{2} \mathrm{SO}_{4} 5^{\prime}+$ água aquecida a $100{ }^{\circ} \mathrm{C} 1^{\prime}$ & $76,0 \mathrm{a}$ & $24,0 \mathrm{a}$ & $00 \mathrm{~b}$ & $0,0 \mathrm{a}$ \\
\hline T5- Testemunha & $5,3 b$ & $1,3 \mathrm{a}$ & $89,3 a$ & $4,1 \mathrm{a}$ \\
\hline CV (\%) & 17,46 & 69,17 & 15,65 & 90,57 \\
\hline
\end{tabular}

*Médias seguidas pela mesma letra numa mesma coluna não diferem significativamente entre si pelo teste de Tukey a $5 \%$ de probabilidade. 
A baixa percentagem de germinação das sementes de 0 . arborea deveu-se ao ataque de fungos, causando a morte do embrião após a emissão da radícula. Marques et al. (1997) também verificaram severo ataque de fungos em sementes dessa espécie, sugerindo o uso de pré-tratamento com fungicida nas sementes. (Tabela 2).

Tabela 2. Índices percentuais de germinação $(G)$, sementes duras $(D)$, sementes intumescidas (E) e sementes deterioradas (Dt) ao fim da contagem de germinação das sementes de Ormosia arborea (Vell.) Harms.

\begin{tabular}{|c|c|c|c|c|}
\hline Tratamentos & G (\%) & $E(\%)$ & $\mathrm{D}(\%)$ & $\mathrm{Dt}(\%)$ \\
\hline T1- Água a $100^{\circ} \mathrm{C} 1$ ' & $01 \mathrm{c}$ & $04 a b$ & $95 \mathrm{a}$ & $05 \mathrm{~b}$ \\
\hline $\mathrm{T} 2-\mathrm{H}_{2} \mathrm{SO}_{4} 10^{\prime}$ & $81 \mathrm{a}$ & $09 a b$ & $08 \mathrm{c}$ & $04 \mathrm{~b}$ \\
\hline $\mathrm{T} 3-\mathrm{H}_{2} \mathrm{SO}_{4} 5^{\prime}+$ água aquecida a $100^{\circ} \mathrm{C} 0,5^{\prime}$ & $19 b$ & $09 \mathrm{ab}$ & $52 b$ & $23 a$ \\
\hline $\mathrm{T} 4-\mathrm{H}_{2} \mathrm{SO}_{4} 5^{\prime}+$ água aquecida a $100^{\circ} \mathrm{C} 1{ }^{\prime}$ & $21 b$ & $12 \mathrm{a}$ & $45 b$ & $27 \mathrm{a}$ \\
\hline T5- Testemunha & $00 \mathrm{c}$ & $00 \mathrm{~b}$ & $100 \mathrm{a}$ & $00 \mathrm{~b}$ \\
\hline CV (\%) & 19,06 & 54,15 & 11,19 & 48,61 \\
\hline
\end{tabular}

*Médias seguidas pela mesma letra numa mesma coluna não diferem significativamente entre si pelo teste de Tukey a $5 \%$ de probabilidade.

Nas sementes da espécie de 0 . arborea, 0 tratamento com $\mathrm{H}_{2} \mathrm{SO}_{4}$ 10' (T2) proporcionou maior percentual de germinação, acarretando em um menor percentual de sementes duras e deterioradas (Tabela 2).

0 tratamento com Água a $100{ }^{\circ} \mathrm{C} 1^{\prime}(\mathrm{T} 1)$ e testemunha (T5) para espécie de 0 . arborea, apresentaram menor percentual de germinação, não diferindo estatisticamente entre si (Tabela 2).

Para a espécie de 0 . arborea, o maior percentual de sementes deterioradas, para essa espécie, foi observado para os tratamentos $\mathrm{H}_{2} \mathrm{SO}_{4} 5^{\prime}$ + água aquecida a $100{ }^{\circ} \mathrm{C}$ 0,5' (T3) e $\mathrm{H}_{2} \mathrm{SO}_{4} 5^{\prime}$ + água aquecida a $100^{\circ} \mathrm{C} 1^{\prime}$ (T4), não diferindo estatisticamente (Tabela 2).

Lopes et al. (2004) trabalhando com quebra de dormência em 0 . arborea concluíram que as sementes possuem reduzida velocidade e baixa porcentagem de germinação, recomendando tratamentos com escarificação mecânica seguidos de imersão em ácido sulfúrico por períodos entre 1 e 20 minutos, por serem eficientes na redução da dormência das sementes. Também defendem que a escarificação mecânica associada à pré-embebição sob temperatura mais elevada e maior tempo de exposição aumentam a deterioração das sementes.

Os maiores valores do coeficiente de variação nas tabelas 1 e 2 para percentual de sementes intumescidas e deterioradas foi devido à alta variação dos valores encontrados, obtendo tratamentos com menor índice de incidência, comparados a outros em que os valores foram maiores. Esta variação está relacionada, em função da variação genética embutida nas sementes e em função das condições de desenvolvimento e amadurecimento dos frutos.

As sementes de $A$. mangium apresentaram um menor percentual de plântulas anormais para os tratamentos $\mathrm{H}_{2} \mathrm{SO}_{4} 5^{\prime}+$ água aquecida a $100^{\circ} \mathrm{C} 0,5^{\prime}$ (T3) e $\mathrm{H}_{2} \mathrm{SO}_{4} 5^{\prime}+$ água aquecida a $100^{\circ} \mathrm{C} 1^{\prime}$ (T4) (Figura 1). A maior presença de plântulas anormais foi observada para a testemunha que obteve estatisticamente um menor percentual germinativo (Tabela 1), devido à resistência tegumentar, visto que a testemunha não obteve qualquer tratamento prévio para quebra da dormência.

Os tratamentos com uso do ácido seguido de água fervente (T3 e T4) para a espécie de 0 . arborea proporcionaram maior percentual de sementes deterioradas, devido, principalmente, ao ataque de fungos, e maior percentual de plântulas anormais, em função do impedimento da germinação e em alguns casos com a morte do embrião. $\mathrm{O}$ tratamento $\mathrm{H}_{2} \mathrm{SO} 4$ 10' (T2) obteve melhor percentual germinativo (Tabela 2) com um menor percentual de plântulas anormais conforme Figura 1.

0 início da germinação das sementes de 0 . arborea foi mais tardio, por volta do oitavo dia com início da estabilização apenas a partir do $20^{\circ}$ dia após semeadura (Figura 2). 
Figura 1. Percentual de plântulas anormais de Acacia mangium Willd e Ormosia arborea (Vell.) Harms quanto aos tratamentos onde: número de plântulas anormais / número total de plântulas x 100.

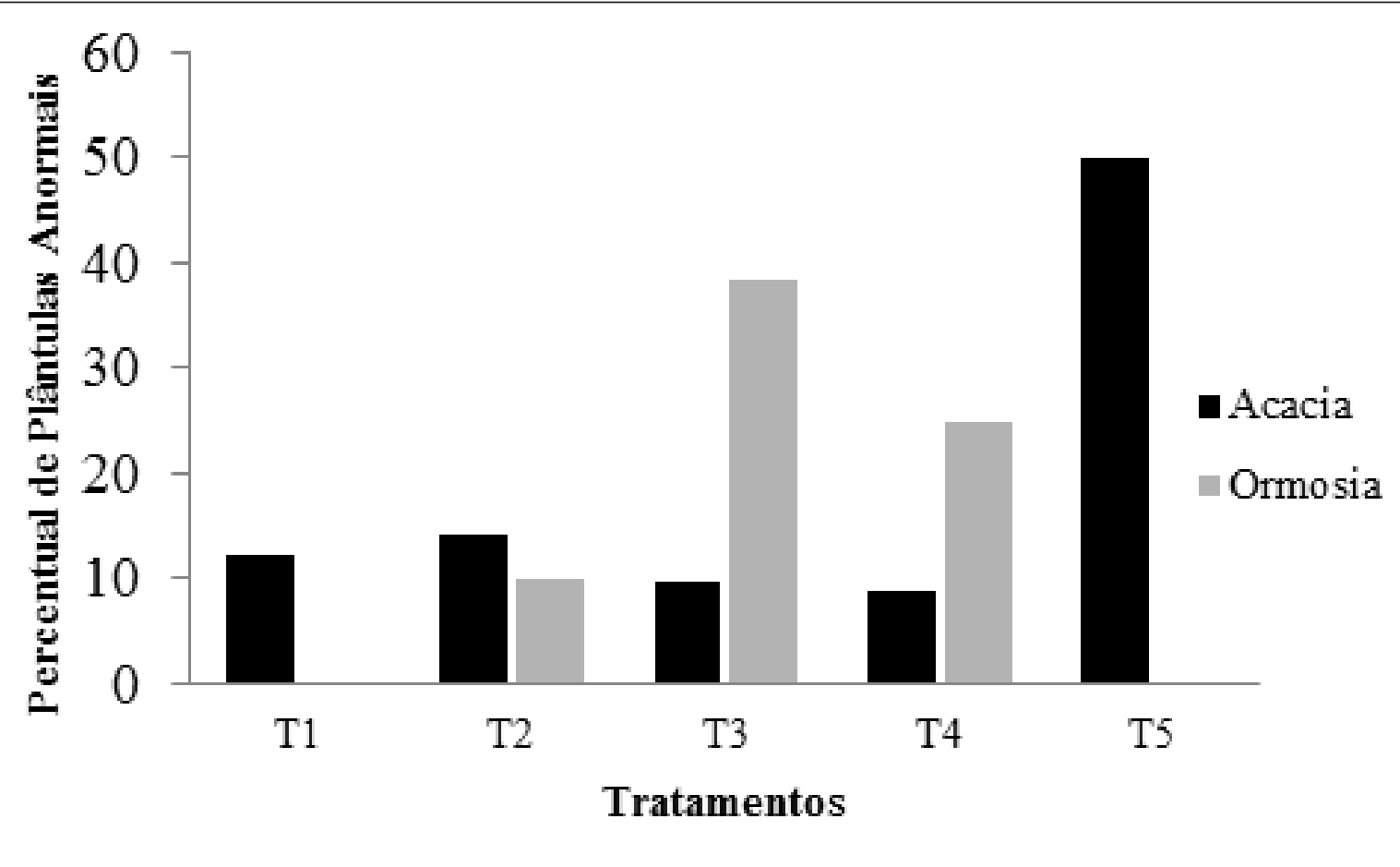

Figura 2. Número de sementes germinadas de Acacia mangium Willd. e Ormosia arborea (Vell.) Harms ao longo do tempo de execução do experimento.

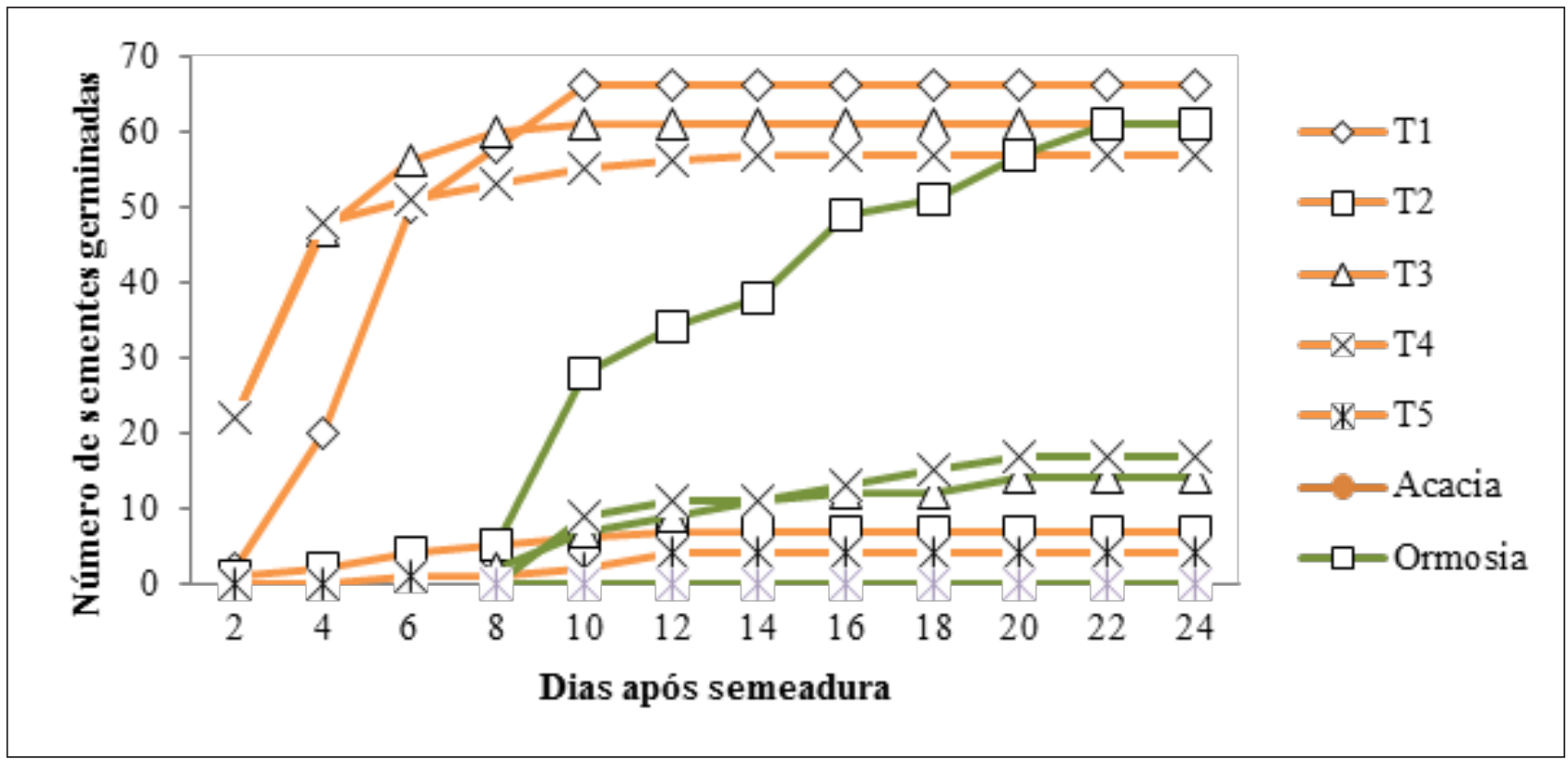

A germinação das sementes de $A$. mangium foi iniciada logo nos primeiros dias com maior intensidade nos tratamentos com o ácido e água fervente (T3 e T4), estabilizando-se também mais rapidamente enquanto 0 tratamento apenas com água fervente há 1 ' (T1) obteve germinação inicial mais retardada, com maior tempo até estabilização (Figura 2).
Para 0 índice de velocidade de emergência (Tabela 3), observa-se que os tratamentos com o uso de ácido sulfúrico seguido de água fervente (T3 e T4) foram os que determinaram maior velocidade de germinação em sementes de $A$. mangium com menores resultados para testemunha e o tratamento apenas com ácido (T2) o que confere com os demais resultados 
(Tabela 1, Figura 2). 0 tratamento com água fervente a $100{ }^{\circ} \mathrm{C}$ por 1 ' (T1) foi estatisticamente semelhante aos com o uso do ácido sulfúrico seguido de água fervente (T3 e T4), invertendo os valores encontrados quanto ao percentual de germinação (Tabela 1).

0 uso de ácido sulfúrico seguido de água fervente (T3 e T4) se mostrou muito eficiente quando comparados pelo teste estatístico, apresentando melhores resultados apenas para as sementes de $A$. mangium e sendo estatisticamente semelhante para percentual de germinação e IVG quando comparados ao tratamento em água fervente (T1), que é o recomendado por diferentes autores como Smiderle et al. (2005), Tavares et al. ( 2016).

As sementes de 0 . arborea obtiveram maior IVG quando tratadas com $\mathrm{H}_{2} \mathrm{SO}_{4} 10^{\prime}$ (T2), apresentando 0 valor de 15,53. 0 tratamento com água fervente a 100 'C por 1' (T1) foi comparável a testemunha. Os demais tratamentos promovem a quebra da dormência, porém com baixa eficiência (Tabela 3).

Tabela 3. Índice de velocidade de germinação (IVG) de sementes de Acacia mangium Willd. e Ormosia arborea Vell. Harms em papel germitest submetidas a cinco tratamentos de escarificação.

\begin{tabular}{|c|c|c|}
\hline \multirow{2}{*}{ Tratamentos } & \multicolumn{2}{|c|}{ IVG } \\
\hline & Acácia & Ormosia \\
\hline T1- Água a $100^{\circ} \mathrm{C} 1{ }^{\prime}$ & $24,3 a$ & $0,00 \mathrm{c}$ \\
\hline $\mathrm{T} 2-\mathrm{H}_{2} \mathrm{SO}_{4} 10^{\prime}$ & $2,53 b$ & $15,53 a$ \\
\hline $\mathrm{T} 3-\mathrm{H}_{2} \mathrm{SO}_{4} 5^{\prime}+$ água aquecida a $100^{\circ} \mathrm{C} 0,5^{\prime}$ & $36,0 \mathrm{a}$ & $3,87 \mathrm{bc}$ \\
\hline $\mathrm{T} 4-\mathrm{H}_{2} \mathrm{SO}_{4} 5^{\prime}$ a água aquecida a $100^{\circ} \mathrm{C} 1^{\prime}$ & 35,9 a & $4,43 b$ \\
\hline T5- Testemunha & $0,77 b$ & $0,00 \mathrm{c}$ \\
\hline CV (\%) & 21,09 & 30,96 \\
\hline
\end{tabular}

*Médias seguidas pela mesma letra numa mesma coluna não diferem significativamente entre si pelo teste de Tukey a $5 \%$ de probabilidade.

Em geral as sementes, potencialmente, podem transportar os organismos fitopatogênicos, embora a transmissão de inúmeros deles, dessa maneira, não seja conhecida (Carvalho; Nakagawa, 2000), o que confere com 0 encontrado nas sementes de 0 . arborea que mesmo sem exposição ao solo apresentaram reduzida germinação devido à contaminação por fitopatógenos possivelmente presentes na semente.

Sementes de 0 . arborea necessitam de tratamento pré-germinativo com fungicida para evitar contaminação do embrião.

Diante do exposto, conclui-se que as sementes das espécies estudadas apresentam dormência física ou tegumentar e que os tratamentos mais eficientes para a superação da dormência das sementes da $A$. mangium é com água a $100{ }^{\circ} \mathrm{C} 1^{\prime}, \mathrm{H}_{2} \mathrm{SO}_{4} 5^{\prime}+$ água aquecida a $100{ }^{\circ} \mathrm{C} 0,5^{\prime}$ e $\mathrm{H}_{2} \mathrm{SO}_{4} 5^{\prime}+$ água aquecida a $100{ }^{\circ} \mathrm{C}$ 1' (T1, T3 e T4) e O. arborea com $\mathrm{H}_{2} \mathrm{SO}_{4}$ 10' (T2). Portanto, os métodos indicados acima de acordo com a espécie poderão ser utilizados para produção de mudas.

\section{REFERÊNCIAS BIBLIOGRÁFICAS}

Berger, A.P.D.A.; Ranal, M.A.; Santana, D.G.D. Variabilidade na dormência relativa dos diásporos de Lithraea molleoides (Vell.). Ciência Florestal, 2014, 24, 2, 325-337.

Carvalho, N.M.; Nakagawa, J. Sementes: ciência tecnologia e produção. 4.ed. Jaboticabal: FUNEP, 2000. $588 p$.

Carvalho, J.C.; Santos, E.B.; Reis, A.R.S.; Reis, L.P.; Santos, J.X. Efeito de tratamentos pré-germinativos e substratos na germinação e crescimento de plântulas de mogno-brasileiro e africano. Biota Amazônia. 2016, 6, 3, 84-88.

Carvalho, N.M.; Nakagawa, J. Sementes: ciência, tecnologia e produção. 5.ed. Jaboticabal: FUNEP, 2012. $590 \mathrm{p}$.

Costa, P.A.; Lima, A.L.S.; Zanella, F.; Freita, H. Quebra de dormência em sementes de Adenanthera pavonina L. Pesquisa Agropecuária Tropical. 2010, 40, 1, 83-88. 
Cruz, E.D.; Carvalho, J.E.U.; Queiroz, R.J.B. Scarification with sulphuric acid of Schizolobium amazonicum Huber ex Ducke seeds - Fabaceae. Scientia Agricola, 2007, 64, 3, 308-313.

Freitas, A.R.; Lopes, J.C.; Matheus, M.T.; Mengarda, L.H.G; Venancio, L.P.; Caldeira, M.V.W. Superação da dormência de sementes de jatobá. Pesquisa Florestal Brasileira. 2013, 33, 73. 85-90.

Freire, J.M.; Ataíde, D.H.S.; Rouws, J.R.C. Superação de Dormência de Sementes de Albizia Pedicellaris (DC.) L. Rico. Floresta e Ambiente. 2016, 23, 2, 251257.

Ferreira, D.F. Sisvar: a guide for its bootstrap procedures in multiple comparisons. Ciência e Agrotecnolgia, 2014, 38, 2, 109-112.

Giachini, R.M.; Lobo, F.; Albuquerque, M.C.F.; Ortíz, C.E.R. Influência da escarificação e da temperatura sobre a germinação de sementes de Samanea tubulosa (Benth.) Barneby \& J.W. Grimes (sete cascas). Acta Amazônica. 2010, 40, 1, 75-80.

Kramer, P.J.; Kozlowski, T. Fisiologia das árvores. Lisboa: Fundação Calouste Gulbenkian, 1972. 745 p.

Ladeia, E.S.; Coelho, M.F.B.; Azevedo, R.A.B.; Albuquerque, M.C.F. Procedência do fruto e substratos na germinação de sementes de Pseudobombax longiflorum (Mart. et Zucc.) A. Robyns. Pesquisa Agropecuária Tropical. 2012, 42, 2, 174- 180.

Lopes, J.C.; Dias, P.C.; Macedo, C.M.P. Tratamentos para superar a dormência de sementes de Ormosia arbórea (Vell.) Harms. Revista Brasil Florestal. 2004, $80,25-35$

Lucena, J.S.; Silva, J.R.B; Barbosa, R.C.A.; Santos, L.L.Q.; Medeiros, F.E.A. Quebra de dormência e germinação de sementes florestais sob a influência de campo magnético. Revista Técnica em Sistemas Agroindustriais. 2016, 2, 1, 12 p.

MAguire, J.D. Speed of germination-aid in selection and evaluation for seedling emergence and vigor. Crop Science, 1962, 2, 1, 176-177.
Marques, M.A.; Rodrigues, T.J.D.; Alves, L.M.T. Métodos para a superação da dormência de sementes de Ormosia arborea (Vell.) Harms. Informativo Abrates, 1997, 7, 1/2, 207.

Martins, C.C.; Nakagawa, J. Germinação de sementes de Stryphnodendron adstringens (Mart.) Coville de diferentes origens submetidas a tratamentos para superação de dormência. Revista Árvore. 2008, 32, 6, 1059-1067.

Nakagawa, J. Testes de vigor baseados na avaliação das plântulas. In: Vieira, R. D.; Carvalho, N. M. (Ed.). Testes de vigor em sementes. Jaboticabal: FUNEP, 1994. p. 49-86.

Tavares, S.R.L; Franco, A.A.; Silva, E.M.R. Produção de Mudas de Acacia Mangium Willd Noduladas e Micorrizadas em Diferentes Substratos. HOLOS. 2016, Ano 32, Vol. 4.

Reis, G.G.; Freitas, S.C. Germinação de sementes de tento (Ormosia arbórea (Vell.) Arms. LeguminosaeFaboidae). Revista Arvore, 1985, 9, .2, 127-133.

Sampaio, F.M.; Couto, R.S.; Silva, A.C.; Silva, A.C.A; Silva, S.A.A.; Teixeira, L.A. Influência de Diferentes Substratos Associados a Métodos de Superação de Dormência na Germinação e Emergência de Sementes de Jatobá (Hymenaea courbaril L.). Revista Farociência, 2015, 2, 1 .

Santos, A.L.F.; Freire, J.M.; Pina-Rodrigues, F.C.M. Avaliação de métodos para superação de dormência de sementes de leguminosas arbóreas utilizadas na recuperação de áreas degradadas. Serepédica: Embrapa Agrobiologia; Boletim de Pesquisa e Desemvolvimento n. 76, 2011.

Smiderle, O.J.; Mourão Junior, M.; Sousa, R.C.P.; Tratamentos pré germinativos em sementes de acácia. Revista Brasileira de Sementes. 2005, 27, 1, 78-85. 